Article

\title{
Improved Thermal Processing of Polylactic Acid/Oxidized Starch Composites and Flame-Retardant Behavior of Intumescent Non-Wovens
}

\author{
Muhammad Maqsood $($ and Gunnar Seide *(D) \\ Aachen Maastricht Institute for Biobased Materials, Faculty of Science and Engineering, Maastricht University, \\ Urmonderbaan 22, 6167 RD Geleen, The Netherlands; muhammad.maqsood@maastrichtuniversity.nl \\ * Correspondence: gunnar.seide@maastrichtuniversity.nl
}

Received: 4 March 2020; Accepted: 19 March 2020; Published: 20 March 2020

check for updates

\begin{abstract}
Thermoplastic processing and spinning of native starch is very challenging due to (a) the linear and branched polymers (amylose and amylopectin) present in its structure and (b) the presence of inter-and-intramolecular hydrogen bond linkages in its macromolecules that restrict the molecular chain mobility. Therefore, in this study, oxidized starch (OS) (obtained after oxidation of native starch with sodium perborate) was melt-blended with polylactic acid (PLA) polymer to prepare PLA/OS blends that were then mixed together with ammonium polyphosphate (APP), a halogen-free flame retardant (FR) used as acid donor in intumescent formulations on twin-screw extruder to prepare PLA/OS/APP composites. OS with different concentrations also served as bio-based carbonic source in intumescent formulations. PLA/OS/APP composites were melt spun to multifilament fibers on pilot scale melt-spinning machine and their crystallinity and mechanical properties were optimized by varying spinning parameters. The crystallinity of the fibers was studied by differential scanning calorimetry and thermal stabilities were analyzed by thermogravimetric analysis. Scanning electron microscopy was used to investigate the surface morphology and dispersion of the additives in the fibers. Needle-punched non-woven fabrics from as prepared melt-spun PLA/OS/APP fibers were developed and their fire properties such as heat release rate, total heat release, time to ignition, residual mass \% etc. by cone calorimetry test were measured. It was found that PLA/OS/APP composites can be melt spun to multifilament fibers and non-woven flame-retardant fabrics produced thereof can be used in industrial FR applications.
\end{abstract}

Keywords: thermal processing; flame-retardant; composites; non-wovens; polylactic acid

\section{Introduction}

Bioplastics issued from renewable resources represent an interesting alternative to reduce carbon footprints instead of using polymers made of fossil carbon [1]. Therefore, significant progress in the development of bio-based polymers with renewable feedstock has generated great interest in the polymer industry [2]. Starch is one of the abundant biopolymers with diverse applications in many fields such as food processing, sizing material in textiles as binding agent to reduce friction and in vat dyes for the printing of $100 \%$ cotton fabrics by virtue of its cost effectiveness, biodegradability and renewability [3]. It consists of amylose and amylopectin. Amylose is a linear polymer consisting of $\alpha-(1-4)$ glucose units, while amylopectin is a branched polymer consisting of $\alpha-(1-4)$ glucose units with intermittent divisions of $\alpha-(1-6)$ connections [4]. Therefore, thermoplastic processing of starch is difficult due to the presence of intermolecular and intramolecular hydrogen bond linkages in its macromolecules that restrict the molecular chain movement due to the presence of resilient 
interactive forces [5]. Such interactive forces are repelled by the use of plasticizers such as glycol, glycerol, sorbitol or urea that weaken the hydrogen bonds present within the macromolecules and thermoplastic processing of starch is improved [6]. These plasticizers disrupt the crystalline structure of starch macromolecules and allows free molecular chain movement by nullifying the resilient interactive forces by a process called gelatinization [7]. However, the foremost disadvantage of using plasticizers in starch is the emergence of a hydrophilic characteristic that induces poor water resistance in the polymer hence negatively impacts the mechanical properties of polymer [8]. The other drawbacks associated with native starch are lack of fluidity and higher viscosity that limits its uses in many technical applications [9].

Such shortcomings can be remedied by the oxidation of starch by using oxidizing agents [10]. Starch oxidation results in de-polymerization by the hydrolysis of glucose units hence oxidized starches present low viscosities at higher concentrations: a property desired for thermoplastic processing of starch [11]. Many oxidizing agents for starch oxidation have been used in the past such as sodium hypochlorite, hydrogen peroxide and ammonium persulfate. However, sodium hypochlorite has been found to be the most efficient one and widely used in industrial production, but in the recent past, this oxidizing agent has been abandoned due to the formation of hazardous chlorinated byproducts that are harmful to the environment [12]. Therefore, we used maize starch that was oxidized by sodium perborate (SPB) which is an efficient and environment-friendly oxidizing agent for the oxidation of native starch. In practice, SPB is not only cost effective but also presents distinctive benefits such as being available as a solid form of hydrogen peroxide [13]. However, SPB has proven to be a better alternative to hydrogen peroxide since the former has not only provided superior stability at higher temperatures but also proven to be an efficient source of per hydroxyl anions, superoxide and active oxygen [14].

Blending two different polymers not only can offer valuable properties but also a new composite material can be developed that can present desired functionality for a certain application [15]. Polylactic acid (PLA) is a linear aliphatic polyester [16] that is derived from renewable resources and one of the most important bio-based polymers with attractive physical and performance properties can serve as an alternative to petroleum based polymers in many applications [17]. The blending of starch and PLA will not only make the composite material cost effective but also certain functional properties can be enhanced such as flame retardancy [18]. Although PLA is less flammable than other synthetic thermoplastics [19] in its pure form by virtue of having higher limiting oxygen index (24-26) than other polyesters (20-22) and lower peak heat release rate, PLA is still combustible, which limits its uses in many flame-retardant applications [20]. To improve the flame retardancy of PLA, intumescent flame retardants (IFRs) present an extremely efficient approach through which a char layer is formed on the polymer surface that not only can protect it from further burning but also restricts the passage of heat, oxygen and volatile compounds to the sight of burning [21]. Although, IFRs generally contain a petroleum based carbonic source together with a halogen-free acidic source, but in the recent past, a more sustainable approach towards flame retardancy has been promoted by using biopolymers that contain a bio-based carbonic source [22]. Starch could be a suitable contender as a bio-based carbonic source in intumescent formulations by virtue of its natural charring capability and presence of excessive polyhydric compounds. Wang et al. used starch as natural charring agent in PLA foams [23] however, the spinning of PLA/starch compounds containing intumescent formulations is still unknown.

Therefore, in this study we have investigated the melt spinnability of PLA/oxidized starch (OS) composites containing halogen free intumescent flame-retardants with OS being a bio-based carbonic source presenting sustainable approach towards flame retardancy. We used maize starch that was oxidized by sodium perborate (SPB) which is an efficient and environment friendly oxidizing agent for the oxidation of native starch to improve its thermoplastic processing and spinnability. Composites were melt-spun to multifilament fibers on pilot-scale melt spinning machine and fibers were then needle-punched to form non-woven structures. The changes in fiber crystallinity and mechanical properties were measured in response to the variations in spinning process parameters. We also 
tested the thermal stability of fibers by thermogravimetric analysis, while surface morphology and dispersion of the additives was recorded by scanning electron microscopy. The fire characteristics such as time to ignition, heat release rate, and total heat release were tested by cone calorimetry as standard testing methods.

\section{Materials and Methods}

\subsection{Materials}

Oxidized starch (OS) 400L-NF, a white fine powder, containing $20 \mathrm{mg} \mathrm{kg}^{-1}$ of SPB as an oxidizing agent was kindly provided by Roquette Freres SA (Lestrem, France). PLA Luminy L130 which is a highly-crystalline polymer (L-isomer $\geq 99$ ) with a density of $1.24 \mathrm{~g} \mathrm{~cm}^{-3}$ and melting temperature of $175-180{ }^{\circ} \mathrm{C}$ was purchased from Total-Corbion NV (Gorinchem, Netherlands). Halogen-free flame retardant (FR, Exolit AP 422) having decomposition temperature higher than $275^{\circ} \mathrm{C}$ was attained from Clariant AG (Muttenz, Switzerland). Exolit AP 422 is a fine-particle ammonium polyphosphate (APP) containing 31\% $(\mathrm{w} / \mathrm{w})$ phosphorous and $14 \%(\mathrm{w} / \mathrm{w})$ nitrogen, having density of $1.9 \mathrm{~g} \mathrm{~cm}^{-3}$ and average particle size of $17 \mu \mathrm{m}$, used as acid donor in intumescent formulations. PLA, APP and OS were vacuum dried at $100^{\circ} \mathrm{C}$ for $4 \mathrm{~h}$ before compounding.

\subsection{Preparation of Composites}

PLA/OS/APP composites were prepared on twin-screw extruder $\left(\mathrm{ZSK} \mathrm{Mc}^{18}\right)$ from Coperion $\mathrm{GmbH}$ (Stuttgart, Germany). OS was mixed together with PLA pellets in four different concentrations, i.e., 1, 3, 5 and $7 \mathrm{wt} \%$ in the first feeding zone which were then compounded together with APP present in the second feeding zone. PLA/OS1/APP10, PLA/OS3/APP10, PLA/OS5/APP10 and PLA/OS7/APP10 composites were prepared at screw rotation speed of $500 \mathrm{rpm}$. The formulations with content of each component $(\mathrm{w} / \mathrm{w})$ of as prepared composites are presented in Table 1 . The temperatures of the three heating zones were kept at $160^{\circ} \mathrm{C}, 170^{\circ} \mathrm{C}$ and $180^{\circ} \mathrm{C}$, respectively.

Table 1. Additives Composition in PLA/OS/APP composites.

\begin{tabular}{ccccc}
\hline No. & Formulations & PLA (wt $\%)$ & OS (wt $\%)$ & APP (wt $\%)$ \\
\hline 1 & PLA/OS1/APP10 & 89 & 1 & 10 \\
2 & PLA/OS3/APP10 & 87 & 3 & 10 \\
3 & PLA/OS5/APP10 & 85 & 5 & 10 \\
4 & PLA/OS7/APP10 & 83 & 7 & 10 \\
\hline PLA = polylactic acid; OS = oxidized starch; APP = ammonium polyphosphate.
\end{tabular}

\subsection{Melt Spinning of Composites}

PLA/OS/APP composite pellets were vacuum dried at $100{ }^{\circ} \mathrm{C}$ for $4 \mathrm{~h}$ prior to melt spinning. Drying the pellets before melt spinning is necessary to control moisture (\%) in the polymer to avoid hydrolysis that can lower the viscosity of the melt and ultimately fiber breakage during spinning can occur. Karl Fischer titrations analyzed by ASTM D6869-17 method confirmed that the moisture content in the pellets were lower than $80 \mathrm{ppm}$. Pilot scale melt spinning machine (Figure 1) with a throughput of few kilograms an hour was used to spin PLA/OS/APP composite pellets to multifilament fibers. The composite pellets were dosed into the hopper of the melt-spinning machine and were then transferred to the extruder where they were melted at a temperature range of $190{ }^{\circ} \mathrm{C}$ to $215^{\circ} \mathrm{C}$. Constant rpm of spin pump ensured a homogeneous supply of the melt to the spinneret die containing 24 monofilament holes. After ejecting from spinneret die, monofilaments were delivered through the quenching section where chilled air running at a velocity of $0.5 \mathrm{~m} \mathrm{~s}^{-1}$ helped in lowering the temperature of the monofilaments. They were joined together into multifilaments by passing through the spin finish before being collected by the take-up roller. The bobbins carrying multifilaments were 
placed in standard atmospheric conditions before further analysis. The spinning parameters used to produce multifilament fibers are presented in Table 2.

Table 2. Spinning parameters to produce multifilament fibers.

\begin{tabular}{cccc}
\hline No. & Factors & \multicolumn{2}{c}{ Unit Value } \\
\hline 1 & Extrusion temperature & ${ }^{\circ} \mathrm{C}$ & 220 \\
2 & Number of spinneret holes & $\mathrm{No}$. & 48 \\
3 & Spinning pump volume per revolution & $\mathrm{cm}^{3} / \mathrm{rev}$ & 1.2 \\
4 & Spinning pump revolution per minute & $\mathrm{rev} / \mathrm{min}$ & 20 \\
5 & Melt density of compounds & $\mathrm{g} / \mathrm{cm}^{3}$ & 1.2 \\
6 & Throughput & $\mathrm{g} / \mathrm{min}^{3}$ & 28.8 \\
7 & Take up roller speed & $\mathrm{m} / \mathrm{min}$ & 500 \\
8 & First drawing roller speed & $\mathrm{m} / \mathrm{min}$ & $600-700$ \\
9 & Second drawing roller speed & $\mathrm{m} / \mathrm{min}$ & $630-800$ \\
10 & Winding speed & $\mathrm{m} / \mathrm{min}$ & 850 \\
11 & Solid state draw ratio & No. & $1.2-1.6$ \\
\hline
\end{tabular}

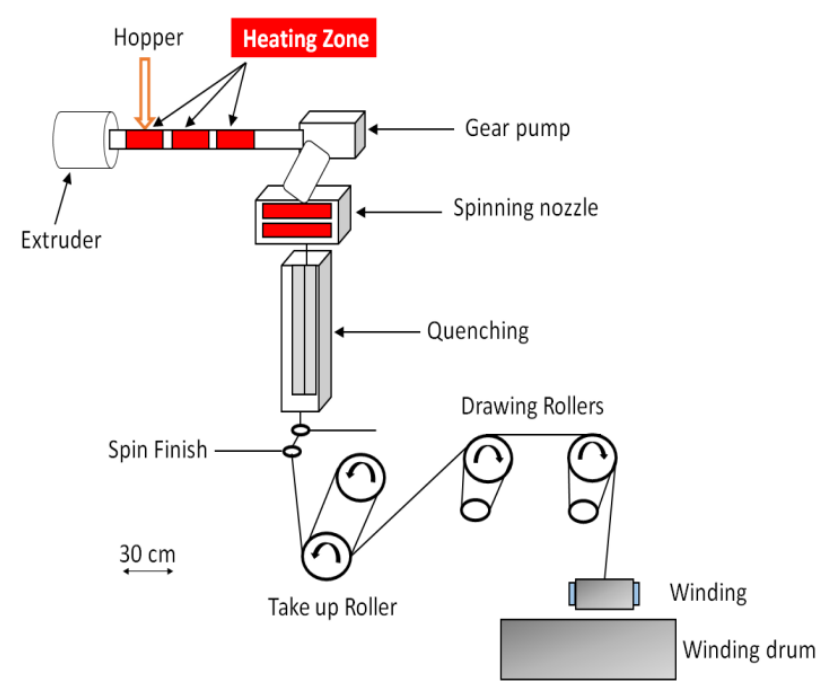

Figure 1. Schematic diagram of pilot scale melt-spinning machine.

\subsection{Scanning Electron Microscopy}

Hitachi S-3200 scanning electron microscope (SEM, Chiyoda, Tokyo, Japan) was used to determine surface morphology and dispersion of the additives in melt spun fibers. Multifilament fibers were first frozen in liquid nitrogen and then were delicately cut with a razor blade to obtain clear SEM images. The cut samples were attached to the silver coated standard specimen stubs which were then sputter coated with gold. The system used for sputter coating was PECS 682, USA. The thickness of the gold sputter coating was $150 \AA$. Fiber samples were examined at a magnification of $1000 \times$ and at an accelerating voltage of $20 \mathrm{kV}$.

\subsection{Apparent Viscosity Measurement}

A Brookfield digital rheometer (Model, DV-III, Middleboro, USA) was used to measure the apparent viscosity of the composite samples. The samples were first dried and then around 5-10 grams from each sample were dispersed in $100 \mathrm{~mL}$ of distilled water to prepare the solutions. The as prepared solutions were stirred continuously for an hour and kept for $15 \mathrm{~min}$ at a temperature of $80^{\circ} \mathrm{C}$. The volume to be used from each sample was adjusted to $100 \mathrm{~mL}$ and the $\mathrm{pH}$ used was 9.0. The solutions were then left for cooling at $25^{\circ} \mathrm{C}$ and then apparent viscosity of each sample was measured at a shear rate of up to $150 \mathrm{~s}^{-1}$. 


\subsection{Mechanical Testing}

Mechanical properties of multifilament fibers such as tenacity (cN/tex) and elongation at break (\%) were tested on Zwick Roell testing machine by using EN ISO 5079 standard method. The specimen lengths $(50 \mathrm{~mm})$ and rate of deformation $\left(50 \mathrm{~mm} \mathrm{~min}^{-1}\right)$ were kept constant for all samples. Ten specimens were prepared from each sample and their average results with standard deviations were recorded.

\subsection{Thermogravimetric Analysis}

Thermal stabilities and residual mass (\%) of the fiber samples up to $500{ }^{\circ} \mathrm{C}$ were analyzed by thermogravimetric analysis using TGA Q5000 equipment (TA Instruments, New Castle, Delaware, USA). Fiber samples of $10-15 \mathrm{mg}$ were heated at a constant rate of $10^{\circ} \mathrm{C} \mathrm{min}^{-1}$ up to $500{ }^{\circ} \mathrm{C}$ under nitrogen atmosphere at a flow rate of $50 \mathrm{~mL} \mathrm{~min}^{-1}$. The initial temperature of measurement for TGA was $20^{\circ} \mathrm{C}$. The temperatures at which maximum decomposition of fibers occurred were noted and the residual mass (\%) of the samples were compared with the initial mass of the samples. Thermogravimetric (TG) curves of the samples were plotted and were analyzed in detail.

\subsection{Differential Scanning Calorimetry}

Thermal properties such as glass transition temperature (Tg), cold crystallization temperature (Tcc), melting temperature (Tm) and crystallinity (\%) of multifilament fibers were investigated by Differential scanning calorimetry (DSC) under nitrogen atmosphere at a stream rate of $50 \mathrm{~mL} \mathrm{~min}{ }^{-1}$. The samples were heated at a constant rate of $10^{\circ} \mathrm{C} \mathrm{min}^{-1}$ starting from $0{ }^{\circ} \mathrm{C}$ to $230{ }^{\circ} \mathrm{C}$ and were then cooled at the same rate followed by heating again as above. The degree of crystallinity $\left(\mathrm{X}_{\mathrm{c}}\right)$ of multifilament fibers was calculated by Equation (1),

$$
X c \%=\frac{\Delta H m-\Delta H c c}{\Delta H f \times W f r} \times 100 .
$$

where $\mathrm{Xc}_{\mathrm{c}}$ corresponds to degree of crystallinity of the sample; $\Delta \mathrm{Hm}$ implies to heat of fusion of the sample; $\Delta$ Hcc corresponds to cold crystallization enthalpy; $\Delta$ Hf relates to the heat of fusion of $100 \%$ crystalline material, and Wfr is the net weight fraction of the polymer. The heat of fusion of $100 \%$ crystalline PLA $(\Delta \mathrm{Hf})$ is approximately $93.6 \mathrm{~J} \mathrm{~g}^{-1}$.

\subsection{Needlepunched Non-Wovens}

Needlepunching is a process by which fibers are mechanically bonded by entangling them together with the barbed needles penetrating through the fibrous web to form non-woven fabrics. Multifilament fibers produced by melt spinning were cut to short fibers and passed through a carding machine: a process by which fibers were opened and homogeneously blended to form fibrous web of uniform areal density. The unbonded and voluminous fibrous web was fed to the needlepunching machine by a pair of feed rollers, and then passed between a pair of perforated plates as shown in Figure 2 . The barbed needles responsible for entangling the fibrous web were arranged on the needle board that was placed on a reciprocating beam operated through an eccentric crank mechanism. In the downward motion, barbed needles ran down through the perforations of the top and bottom bed plates and during the upward motion were withdrawn upwards; therefore, by doing so fibrous webs were mechanically bonded and mechanical strength of the non-woven fabric was improved. The delivery rollers delivered the mechanically bonded non-woven fabric, which was then thermally molded to impart uniform thickness and areal density. 


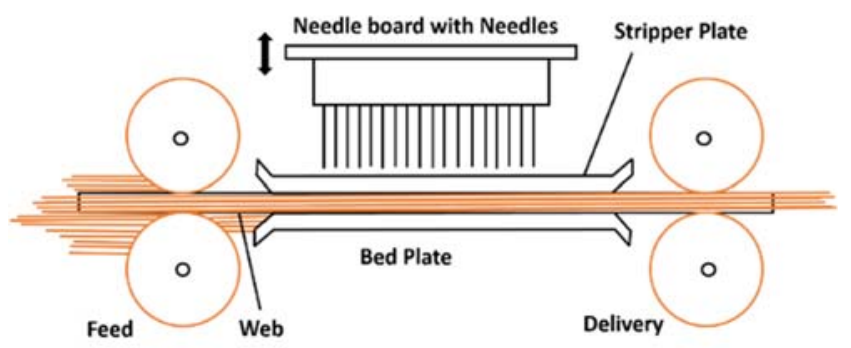

Figure 2. Needlepunching process to form non-woven fabric from fibrous web.

\subsection{Fire Testing}

The cone calorimeter is one of the most important fire testing equipment that is used to measure the heat release rate (HRR) of the sample. The basic principle of this equipment is based on the consumption of oxygen which is considered equivalent to the amount of heat released during combustion. This equipment can also measure the amount of smoke produced during combustion. The non-woven fabric samples with dimensions of $100 \times 100 \times 3 \mathrm{~mm}^{3}$ were prepared to perform a cone calorimetry test, according to ISO 5660 standard testing method, with heat flux of $35 \mathrm{~kW} \mathrm{~m}^{-2}$ by using Stanton Redcroft instrument (Illinois Toolworks, Glenview, IL, USA). The other important fire testing results that can be obtained through this equipment are time to ignition (TTI), total heat release (THR), total smoke production (TSP) and residual mass \% of the sample.

\subsection{Fourier Transform Infrared Spectra (FTIR)}

Fourier transform infrared (FTIR) spectra of non-woven fabrics before and after burning were recorded on a Perkin Elmer Spectrum 1000 FTIR spectrometer at room temperature and the sample powders of around $10 \mathrm{mg}$ were mixed with $200 \mathrm{mg} \mathrm{KBr}$ powder and subsequently a mixture of about $50 \mathrm{mg}$ was pressed to form a tablet for IR measurements. FTIR spectra were recorded in the range of 500 to $4000 \mathrm{~cm}^{-1}$.

\section{Results and Discussion}

\subsection{Measuring Apparent Viscosity of Composites as a Function of Shear Rate}

The apparent viscosity as a function of shear rate of the PLA composite pellets containing OS and APP is depicted in Figure 3. The curves indicated that a significant decrease in apparent viscosity was observed by increasing the shear rate. As the shear rate increased up to $50 \mathrm{~s}^{-1}$, a very intense decrement in apparent viscosity was visible however, after $50 \mathrm{~s}^{-1}$ and up to $150 \mathrm{~s}^{-1}$ shear rate, a minimal decrement in the apparent viscosity was observed. At the same time, increasing OS concentration from 1 to $7 \mathrm{wt} \%$ initially showed a higher apparent viscosity but as the shear rate increased a significant reduction in the apparent viscosity can be seen. The composite pellets containing only $1 \mathrm{wt} \%$ of OS in particular had a very low apparent viscosity after a shear rate of $50 \mathrm{~s}^{-1}$, which even levelled off at shear rate of $100 \mathrm{~s}^{-1}$.

As a comparison, the viscosity of the composite pellets containing native starch with similar compositions (PLA/NS7/APP10) was also measured by the same method. It can be seen in Figure 3 that the apparent viscosity of the composite pellets containing oxidized starch was significantly lower than the apparent viscosity of native starch (both containing equivalent $\mathrm{wt} \%$ of additives) measured at the same parameters. This is attributed to the scission of the glucosidic linkages due to the oxidation caused by the presence of oxidizing agent in the formulations of composite pellets [24]. Scission in the glucosidic linkages is also attributed to the reduction in the molecular weight of the oxidized starch hence its apparent viscosity decreased significantly. The oxidation of starch and an ease in the cleavage of glucosidic linkages shortened the starch chain molecules, which caused breakages in the structure 
and hence the apparent viscosity was decreased significantly [25]. Hence, it was found that the starch's fluidity and higher viscosity could be controlled by using an oxidizing agent.

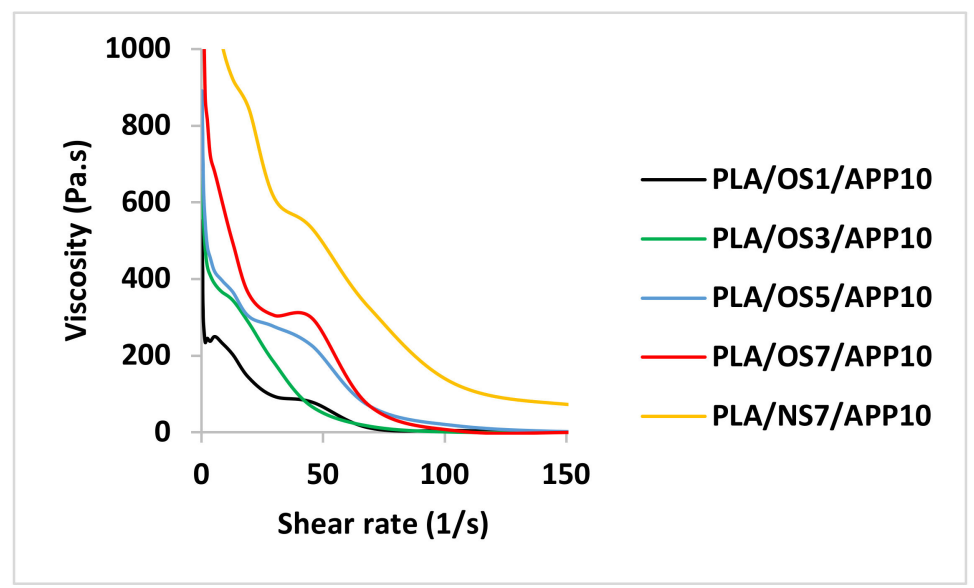

Figure 3. Apparent viscosity of the composite pellets (PLA = polylactic acid; OS = oxidized starch; $\mathrm{APP}=$ ammonium polyphosphate).

\subsection{Multifilament Fibers and Their Mechanical Properties}

The spinning of multifilament fibers from as prepared composites was not only challenging but also it took a while to find the right parameters to make the spinning process stable for continuous winding. The summary of the test results is presented in Table 3 while the mechanical properties of the melt-spun fibers are shown in Figure 4. The tenacity and elongation at break (\%) of the as spun fibers were on the lower side as expected since low crystallinity was induced in the fibers however, the tenacity was gradually improved by increasing the solid state draw ratio (SSDR) of the fibers. Similarly, the initial modulus of the as spun fibers decreased with increasing OS content although the difference was not significant. The tensile strength of melt-spun fibers was significantly improved by increasing the SSDR as a maximum tenacity of $13.4 \mathrm{cN} /$ tex for fibers containing $3 \mathrm{wt} \%$ OS was achieved at SSDR of 1.6. In comparison to other fibers, the tenacity was gradually reduced by increasing the $\mathrm{wt} \%$ of OS at the same SSDR, as 5 and $7 \mathrm{wt} \%$ of OS in PLA fibers could only achieve a tenacity of 11.7 and $10.1 \mathrm{cN} /$ tex, respectively, at the same SSDR of 1.6. The same trend was observed in case of initial modulus of fibers as increasing loading content $\%$ of OS gradually reduced the initial modulus of the fibers. Compared to as spun fibers, the fibers drawn at SSDR $=1.2$, showed higher elongation at break (\%) however, with increasing SSDR (1.4 and 1.6), the elongation at break gradually reduced. These results indicated that the mechanical properties of melt spun fibers were not only dependent on SSDR but loading concentration (\%) of OS also played a significant role in defining the mechanical properties of fibers. Similar findings were reported by Mittal et al. [26] and it was observed that a significant decrease in mechanical properties of fibers occurred by increasing filler content and suggested that a strong interaction between matrix and filler content is required in order to improve mechanical properties of composite fibers. Chapple et al. [27] used hydroxyapatite as nano-filler reinforcement in the PLA matrix and found that mechanical properties of fibers decreased quite significantly at any loading concentration of hydroxyapatite compared to neat PLA fibers, even though the nano-fillers were uniformly distributed within the matrix. 
Table 3. Summary of mechanical properties of melt-spun fibers.

\begin{tabular}{cccc}
\hline Formulation & Draw Ratio & Tenacity (cN/tex) & Elongation at Break (\%) \\
\hline & As spun & $8.4 \pm 1.5$ & $25.9 \pm 5.7$ \\
Neat PLA & SSDR 1.2 & $12.7 \pm 1.2$ & $120.1 \pm 11.8$ \\
& SSDR 1.4 & $14.8 \pm 1.9$ & $95.8 \pm 16.3$ \\
& SSDR 1.6 & $17.3 \pm 1.6$ & $87.4 \pm 15.6$ \\
\hline & As spun & $5.7 \pm 1.7$ & $23.4 \pm 8.2$ \\
PLA/OS1/APP10 & SSDR 1.2 & $8.7 \pm 1.8$ & $88.4 \pm 10.9$ \\
& SSDR 1.4 & $9.4 \pm 1.3$ & $83.7 \pm 17.9$ \\
& SSDR 1.6 & $12.9 \pm 1.5$ & $78.5 \pm 12.6$ \\
\hline & As spun & $5.1 \pm 0.9$ & $20.6 \pm 10.5$ \\
PLA/OS3/APP10 & SSDR 1.2 & $7.4 \pm 1.6$ & $79.2 \pm 18.1$ \\
& SSDR 1.4 & $10.9 \pm 1.5$ & $72.8 \pm 19.5$ \\
& SSDR 1.6 & $13.4 \pm 1.7$ & $68.4 \pm 17.2$ \\
\hline & As spun & $4.7 \pm 1.4$ & $21.9 \pm 12.9$ \\
PLA/OS5/APP10 & SSDR 1.2 & $6.9 \pm 1.3$ & $65.7 \pm 19.6$ \\
& SSDR 1.4 & $8.2 \pm 1.5$ & $60.3 \pm 13.8$ \\
& SSDR 1.6 & $10.6 \pm 1.1$ & $58.8 \pm 16.4$ \\
\hline & As spun & $3.8 \pm 1.7$ & $18.5 \pm 10.1$ \\
PLA/OS7/APP10 & SSDR 1.2 & $6.1 \pm 1.2$ & $59.2 \pm 11.3$ \\
& SSDR 1.4 & $6.4 \pm 1.4$ & $55.9 \pm 10.5$ \\
& SSDR 1.6 & $7.8 \pm 1.8$ & $51.7 \pm 19.2$ \\
\hline
\end{tabular}

PLA = polylactic acid; $\mathrm{OS}=$ oxidized starch; $\mathrm{APP}=$ ammonium polyphosphate.

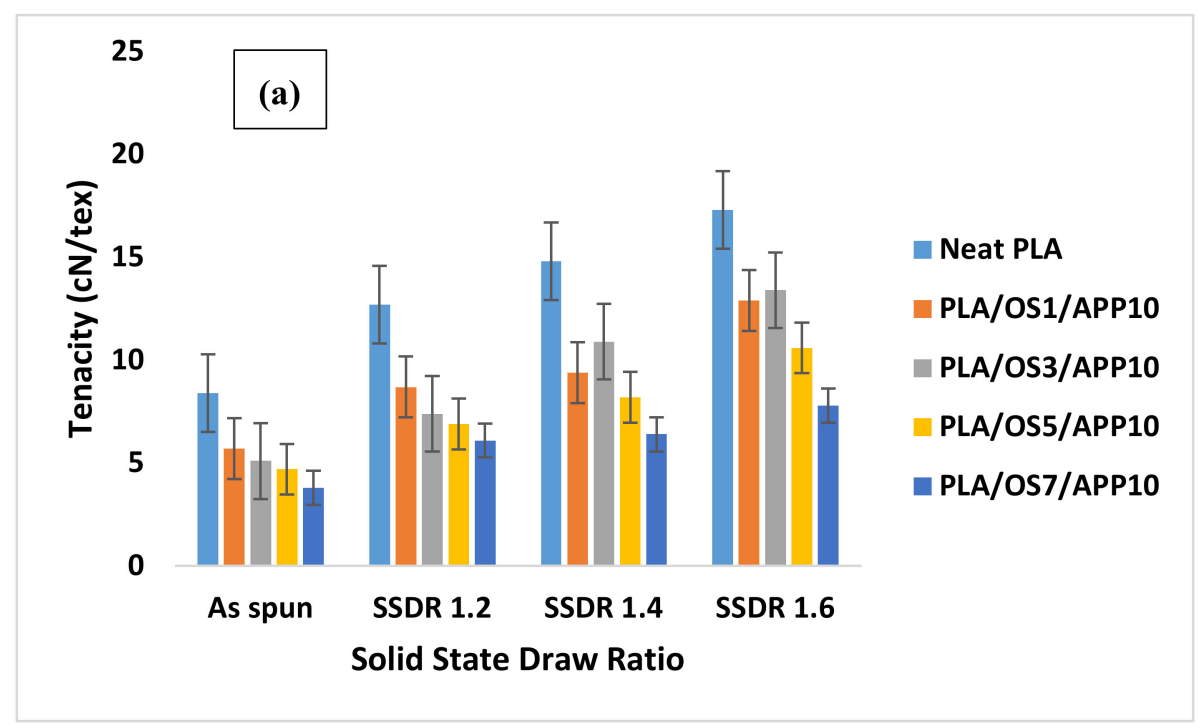

Figure 4. Cont. 


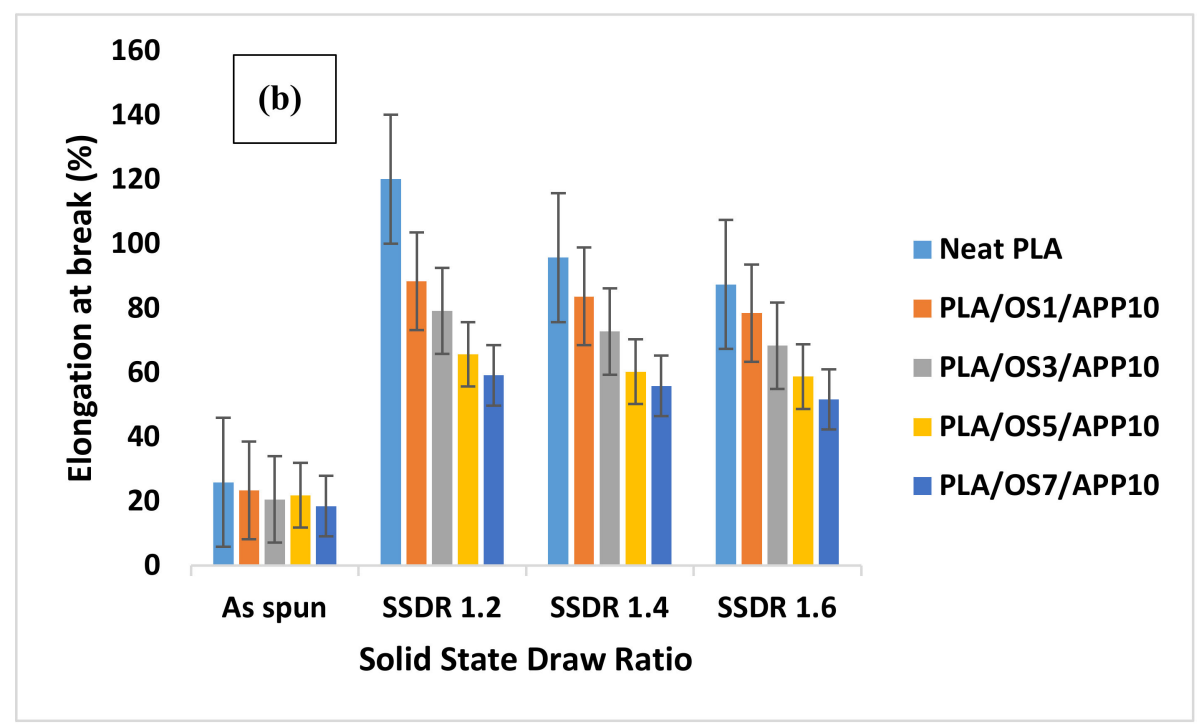

Figure 4. Tenacity (a) and elongation at break (b) of PLA/OS/APP composite fibers (PLA = polylactic acid; OS = oxidized starch; APP = ammonium polyphosphate).

\subsection{Thermal Stability of Multifilament Fibers}

Figure 5 shows the residual mass $(\%)$ of fibers as a function of temperature $\left({ }^{\circ} \mathrm{C}\right)$ of neat PLA and composite fibers. It can be seen in TG plots that the thermal decomposition of fibers started at around $310^{\circ} \mathrm{C}$ and completed around $390^{\circ} \mathrm{C}$. Two distinct zones in the TG curves can be seen such as (a) decomposition of PLA/OS/APP samples due to weight loss in the region of $315^{\circ} \mathrm{C}$ to $390{ }^{\circ} \mathrm{C}$ and (b) residual mass remained as a solid left over in the region of 400 to $500{ }^{\circ} \mathrm{C}$. Table 4 discloses the relationship between the types of samples and the temperature at which $5 \%$ and $50 \%$ mass loss occurred are denoted with $\mathrm{T}_{5}$ and $\mathrm{T}_{50}$, respectively, whereas the temperature corresponding to the maximum rate of mass loss is represented by $\mathrm{T}_{\max }$.

Table 4. Thermogravimetric analysis (TGA) data.

\begin{tabular}{ccccc}
\hline Formulations & $\mathbf{T}_{\mathbf{5}}\left({ }^{\circ} \mathbf{C}\right)$ & $\mathbf{T}_{\mathbf{5 0}}\left({ }^{\circ} \mathbf{C}\right)$ & $\mathbf{T}_{\max }\left({ }^{\circ} \mathbf{C}\right)$ & Residual Mass (\%) \\
\hline Neat PLA & $312.4 \pm 1.9$ & $335.3 \pm 1.2$ & $350.4 \pm 1.5$ & $0.0 \pm 0.0$ \\
PLA/OS1/APP10 & $330.1 \pm 2.4$ & $345.2 \pm 1.9$ & $352.8 \pm 2.1$ & $6.5 \pm 0.9$ \\
PLA/OS3/APP10 & $341.7 \pm 2.1$ & $356.8 \pm 3.5$ & $362.1 \pm 1.3$ & $8.6 \pm 1.4$ \\
PLA/OS5/APP10 & $347.9 \pm 2.7$ & $363.9 \pm 2.1$ & $369.5 \pm 3.3$ & $12.7 \pm 1.8$ \\
PLA/OS7/APP10 & $349.2 \pm 1.3$ & $373.5 \pm 1.7$ & $379.9 \pm 1.9$ & $14.1 \pm 1.2$
\end{tabular}

PLA = polylactic acid OS $=$ oxidized starch; $\mathrm{APP}=$ ammonium polyphosphate; $\mathrm{T}_{5}=$ temperature at $5 \%$ mass loss; $\mathrm{T}_{50}=$ temperature at $50 \%$ mass loss; $\mathrm{T}_{\max }=$ temperature at maximum mass loss.

The decomposition of neat PLA fiber started at $312{ }^{\circ} \mathrm{C}$ and $50 \%$ loss occurred at $335^{\circ} \mathrm{C}$, with no residual mass left at $500{ }^{\circ} \mathrm{C}$. A slightly higher thermal stability was observed for PLA fibers containing $1 \mathrm{wt} \%$ of OS, as thermal decomposition started at around $330.1{ }^{\circ} \mathrm{C}$ and $50 \%$ mass loss occurred at $345.2{ }^{\circ} \mathrm{C}$ with $6.5 \%$ residual mass left at $500{ }^{\circ} \mathrm{C}$. 


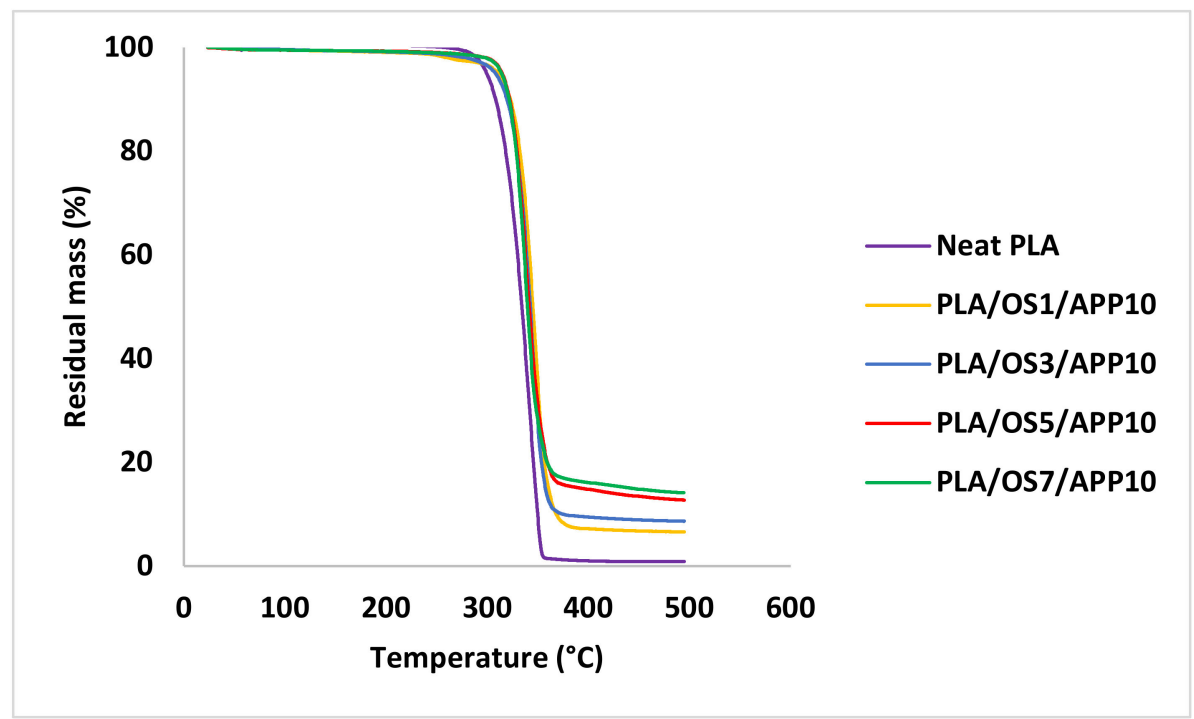

Figure 5. Thermogravimetric curves of fibers (PLA = polylactic acid; OS = oxidized starch; $\mathrm{APP}=$ ammonium polyphosphate).

For PLA fibers containing 3 and $5 \mathrm{wt} \%$ of OS, the initial decomposition temperatures and the temperatures at which $5 \%$ and $50 \%$ weight loss occurred were significantly higher than their corresponding values for PLA fibers containing $1 \mathrm{wt} \%$ of OS as shown in Table 4 , and their residual masses were $8.6 \%$ and $12.7 \%$, respectively. A remarkable increase in thermal stability compared to neat PLA fibers was observed in case of PLA fibers containing $7 \mathrm{wt} \%$ of OS since the residual mass remained at $500{ }^{\circ} \mathrm{C}$ was $14.1 \%$. Higher thermal stabilities and greater residual mass $\%$ of composite fibers are due to the oxidation of starch by the oxidizing agent (SPB) which led to substantial modifications in its molecular structure due to the development and abundance of carbonyl and carboxyl groups which enhanced the thermal stabilities of fibers even at elevated temperatures [7].

\subsection{Thermal Properties and Crystallinity of Multifilament Fibers}

DSC curves of SSD fibers drawn at maximum draw ratio (SSDR $=1.6$ ) are presented in Figure 6 and their respective data are shown in Table 5. The cold crystallization temperature (Tcc) of SSD fibers was in the range of $90.3-107.2{ }^{\circ} \mathrm{C}$. It was observed that with increasing $\mathrm{wt} \%$ of OS from 1 to $7 \mathrm{wt} \%$, Tcc also increased. This changing behavior of Tcc has been well explained by Solarski et al. [28] and concluded that Tcc is vastly dependent on the surface area of the loading particles and the number of particles present in a given area. Moreover, higher concentration of loading particles upsurge the interfacial area of the fibers, which decreases the polymer chain mobility. 


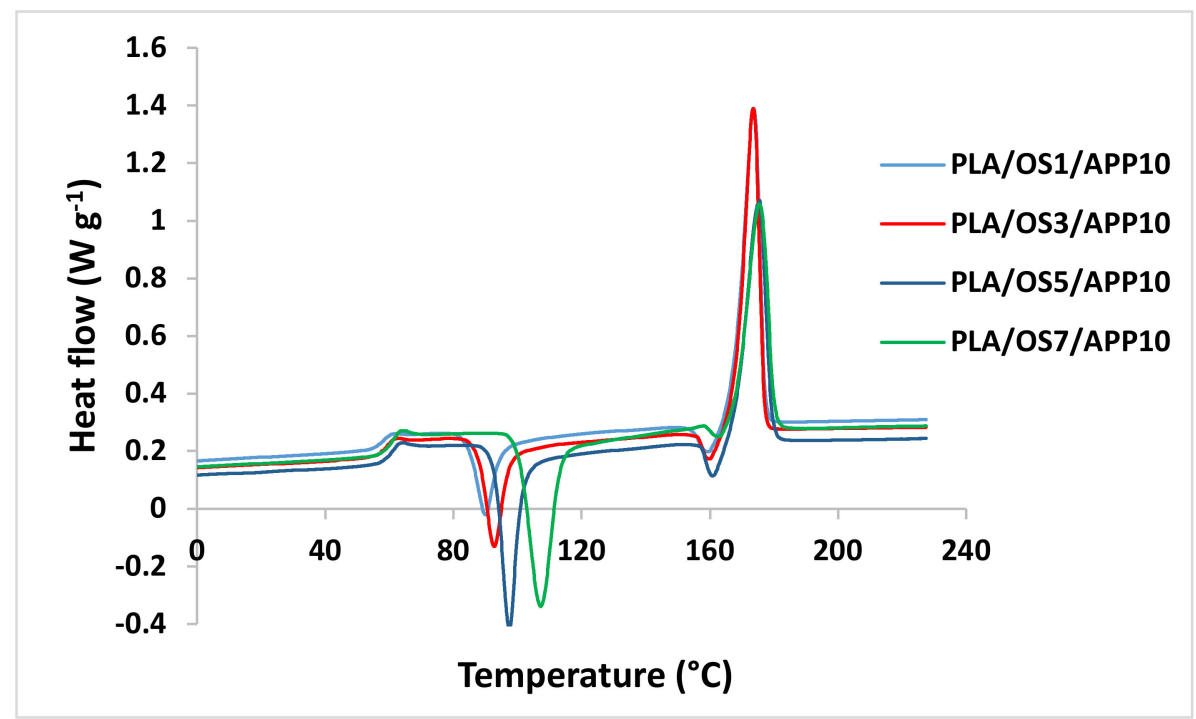

Figure 6. Differential scanning calorimetry (DSC) thermograms of fibers (PLA = polylactic acid; OS = oxidized starch; APP = ammonium polyphosphate).

The increase in the Tcc of fibers due to higher loading concentration of OS can be attributed to comparatively high agglomeration of the additives which decreases the molecular chain mobility; therefore, as a result higher energy is required to activate the polymer chains. At $3 \mathrm{wt} \%$ loading concentration of OS the cold crystallization peak was observed at $95.6{ }^{\circ} \mathrm{C}$ which further increased to $107.2{ }^{\circ} \mathrm{C}$ at $7 \mathrm{wt} \%$ concentration of OS. As explained in previous studies $[26,29]$ the reason for an increase in the cold crystallization temperature with higher loading percentage of particles is due to crystallization of PLA at higher heating temperatures.

Table 5. Thermal properties of fibers by DSC analysis.

\begin{tabular}{ccccccc}
\hline Formulations & $\mathbf{T g}\left({ }^{\circ} \mathbf{C}\right)$ & $\mathbf{T c c}\left({ }^{\circ} \mathbf{C}\right)$ & $\operatorname{Tm}\left({ }^{\circ} \mathbf{C}\right)$ & $\Delta \mathbf{H m}\left(\mathbf{J ~ g}^{-1}\right)$ & $\Delta \mathbf{H c c}\left(\mathbf{J ~ g}^{-1}\right)$ & $\mathbf{X c}(\mathbf{\%})$ \\
\hline PLA/OS1/APP10 & $58.1 \pm 0.4$ & $90.3 \pm 0.9$ & $173.8 \pm 1.1$ & $28.5 \pm 0.7$ & $25.6 \pm 0.2$ & $3.4 \pm 0.4$ \\
PLA/OS3/APP10 & $58.9 \pm 0.7$ & $95.6 \pm 0.5$ & $174.1 \pm 0.9$ & $32.6 \pm 0.4$ & $26.5 \pm 0.9$ & $7.4 \pm 0.2$ \\
PLA/OS5/APP10 & $59.6 \pm 0.3$ & $98.1 \pm 0.8$ & $175.5 \pm 1.5$ & $35.1 \pm 0.8$ & $28.2 \pm 0.1$ & $8.6 \pm 0.5$ \\
PLA/OS7/APP10 & $61.2 \pm 0.6$ & $107.2 \pm 0.7$ & $176.3 \pm 1.2$ & $38.9 \pm 1.2$ & $30.5 \pm 0.6$ & $10.8 \pm 0.4$ \\
\hline
\end{tabular}

$\mathrm{PLA}=$ polylactic acid; $\mathrm{OS}=$ oxidized starch; $\mathrm{APP}=$ ammonium polyphosphate; $\mathrm{Tg}$ = glass transition temperature; $\mathrm{Tcc}=$ cold crystallization temperature; $\mathrm{Tm}=$ melting temperature; $\Delta \mathrm{Hm}=$ heat of fusion of the sample; $\Delta \mathrm{Hcc}=$ cold crystallization enthalpy; $\mathrm{Xc}_{\mathrm{c}}=$ crystallinity $\%$.

At higher loading concentration of OS, an increase in degree of crystallinity was observed. As SSD fibers (SSDR $=1.6$ ) with $1 \mathrm{wt} \%$ loading concentration of OS achieved crystallinity of $3.4 \%$; however, the degree of crystallinity was increased to $10.8 \%$ of SSD fibers containing $7 \mathrm{wt} \%$ of OS. These findings indicated that higher loading concentration of OS improved the crystallinity of SSD fibers and acted as nucleation sites that enhanced the crystallization rate of the fibers [29]. These findings indicated that drawing process enables the macromolecules to be straightened along the axis of the fibers that helps in faster crystallization of the filaments [30]. A slight increase in the melting temperatures (Tm) of the fibers was observed with increasing loading concentration of OS, which indicates that there is a direct correlation between the crystallinity and Tm of the fibers. 


\subsection{Surface Morphology and Diameter of Multifilament Fibers}

The diameters of as spun fibers and SSD fibers are shown in Table 6 that were calculated by Equation (2).

$$
\text { Diameter of fiber }(\mu m)=20 \sqrt{\frac{\text { Linear density of fiber }(\text { dtex })}{\text { Density of polymer }\left(\mathrm{gcm}^{-3}\right) \times \pi}}
$$

The as spun fibers with average diameter of $175 \mu \mathrm{m}$ were obtained as the additives incorporation had no effect on the average diameter of as spun fibers. Similarly, the average diameters of SSD fibers calculated by Equation (2) were in the range of 139-156 $\mu \mathrm{m}$ and their diameters were also not affected by the incorporation of additives. As estimated, the diameter of the SSD fibers decreased quite significantly with increasing SSDR as shown in Table 6.

Table 6. Calculated average diameters of multifilament fibers.

\begin{tabular}{rcccc}
\hline \multicolumn{1}{c}{ Samples } & As-Spun & SSDR 1.2 & SSDR 1.4 & SSDR 1.6 \\
\hline PLA/OS1/APP10 & $175.3 \pm 2.4$ & $156.6 \pm 2.2$ & $147.4 \pm 2.3$ & $139.7 \pm 2.9$ \\
PLA/OS3/APP10 & $177.1 \pm 3.6$ & $157.2 \pm 2.9$ & $148.1 \pm 1.9$ & $139.6 \pm 3.4$ \\
PLA/OS5/APP10 & $174.6 \pm 2.8$ & $155.9 \pm 3.1$ & $149.7 \pm 3.6$ & $139.1 \pm 2.2$ \\
PLA/OS7/APP10 & $176.7 \pm 2.1$ & $156.3 \pm 2.6$ & $147.8 \pm 2.2$ & $140.3 \pm 3.2$ \\
\cline { 2 - 5 } PLA = polylactic acid; OS = oxidized starch; APP = ammonium polyphosphate; SSDR = solid state draw ratio.
\end{tabular}

Compared to as spun fibers, the diameter of SSD fibers decreased $16 \%-20 \%$ for SSDR 1.4 and 1.6 respectively. Surface morphology of SSD fibers (SSDR $=1.6$ ) was studied by SEM analysis (Figure 7). SEM images also confirmed the presence of additives on the surface of fibers drawn at highest SSDR. Even at the maximum loading concentration of the additives ( $7 \mathrm{wt} \%$ of OS), no agglomerates on the surface of SSD fibers can be seen as shown in Figure 7d. No agglomerates were developed because there was better chemical affinity between the polymer and the additives incorporated. The drawback of the agglomerate formation is that the fiber's surface tends to become rough and the fiber's mechanical properties are affected [31]. A well-dispersed additive in the PLA matrix is generally required for smooth process otherwise, aggregation in the polymer matrix can cause fiber defects which can lower the draw-ability of the fibers hence overall mechanical strength and toughness of the fibers can be affected [32].
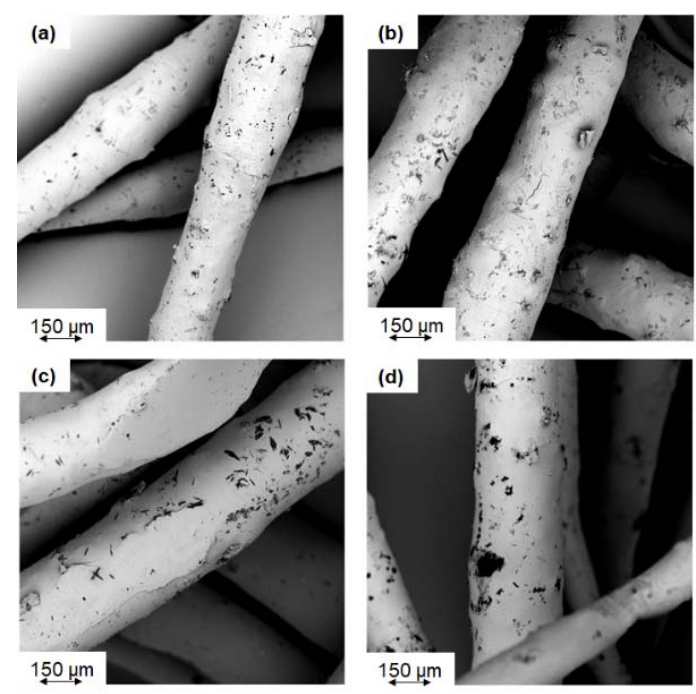

Figure 7. Scanning electron microscope (SEM) images of (a) PLA/OS1/APP10, (b) PLA/OS3/APP10, (c) PLA/OS5/APP10 and (d) PLA/OS7/APP10 multifilament fibers (PLA = polylactic acid; OS = oxidized starch; $\mathrm{APP}=$ ammonium polyphosphate). 


\subsection{Burning Behavior of Non-Wovens by Cone Calorimetry}

Cone calorimetry gives useful insights about the burning behavior of materials in similar situations to real fire scenario and simulate the possible fire hazards [33]. This test was conducted at a heat flux of $35 \mathrm{kWm}^{-2}$ and to evaluate the combustion behavior of samples exposed to this heat flux, peak heat release rate, total heat release and residual mass $\%$ of the samples were determined. HRR and THR curves are presented in Figures 8 and 9 respectively and related data is shown in Table 7 . The samples containing PLA/OS/APP presented lower TTI in comparison to unfilled PLA samples. TTI value decreased with increasing loading content of OS from 1 to $7 \mathrm{wt} \%$ which is ascribed by the increased mass loss rate of OS compared to slower degradation of unfilled PLA. TTI of the samples investigated are presented in Table 7. The sample containing $1 \mathrm{wt} \%$ of OS presented TTI of $65.5 \mathrm{~s}$ while the sample containing $7 \mathrm{wt} \%$ of OS showed the lowest TTI (50.4 s).

Table 7. Cone calorimetry data.

\begin{tabular}{|c|c|c|c|c|c|c|}
\hline Formulation & TTI (s) & $\begin{array}{c}\text { PHRR } \\
\left(\mathrm{kW} \mathrm{m}^{-2}\right)\end{array}$ & $\begin{array}{c}\text { THR } \\
\left(\mathrm{MJ} \mathrm{m}^{-2}\right)\end{array}$ & $\begin{array}{c}\text { Residual Mass } \\
(\%)\end{array}$ & $\begin{array}{c}\text { TSP } \\
\left(\mathrm{m}^{2} \mathrm{~m}^{-2}\right)\end{array}$ & $\begin{array}{c}\text { EHC } \\
\left(\mathrm{kJ} \mathrm{g}^{-1}\right)\end{array}$ \\
\hline PLA & $80.2 \pm 0.9$ & $449.3 \pm 6.2$ & $51.1 \pm 0.5$ & $0.0 \pm 0.0$ & $343.2 \pm 2.5$ & $21.3 \pm 1.60$ \\
\hline PLA/OS1/APP10 & $65.5 \pm 2.6$ & $273.9 \pm 7.5$ & $45.1 \pm 0.9$ & $15.1 \pm 0.5$ & $283.4 \pm 20.4$ & $17.1 \pm 1.56$ \\
\hline PLA/OS3/APP10 & $59.6 \pm 3.8$ & $261.2 \pm 8.8$ & $43.4 \pm 0.4$ & $22.5 \pm 0.7$ & $256.9 \pm 11.5$ & $12.6 \pm 1.34$ \\
\hline PLA/OS5/APP10 & $55.9 \pm 2.5$ & $235.4 \pm 6.3$ & $40.2 \pm 0.8$ & $29.1 \pm 0.4$ & $231.4 \pm 24.1$ & $10.6 \pm 1.43$ \\
\hline PLA/OS7/APP10 & $50.4 \pm 3.4$ & $216.1 \pm 9.5$ & $36.0 \pm 0.4$ & $33.5 \pm 0.9$ & $209.7 \pm 19.9$ & $8.7 \pm 1.18$ \\
\hline
\end{tabular}

$\mathrm{PLA}=$ polylactic acid; $\mathrm{OS}=$ oxidized starch; $\mathrm{APP}=$ ammonium polyphosphate; $\mathrm{TTI}=$ time to ignition; $\mathrm{PHRR}=$ peak heat release rate; THR = total heat release; TSP = total smoke production; EHC = effective heat of combustion.

Figure 8 shows the effect of increasing OS content on HRR of the samples investigated. A significant drop in the HRR of the samples containing PLA/OS/APP was observed; as the sample containing $1 \mathrm{wt} \%$ of OS achieved HRR of $273.9 \mathrm{~kW} \mathrm{~m}^{-2}$ compared to $449.3 \mathrm{~kW} \mathrm{~m}^{-2}$ for the sample containing unfilled PLA. For the sample containing $3 \mathrm{wt} \%$ of OS, HRR declined to $261.2 \mathrm{~kW} \mathrm{~m}^{-2}$, which was further reduced to $216.1 \mathrm{~kW} \mathrm{~m}^{-2}$ by the addition of $7 \mathrm{wt} \%$ of OS. The HRR was significantly reduced due to the char layer produced in the condensed phase on the surface of the samples that protected the samples underneath and effectively reduced the HRR during combustion [30]. The superior fire performance is due to the formation of proficient phosphate layer in the condensed phase that enhanced the stability of the char residues [34].

Figure 9 shows the THR curves of pure PLA and the PLA/OS/APP non-woven fabrics. It indicates that the THR of pure PLA was $51.1 \mathrm{MJ} \mathrm{m}^{-2}$ whereas the PLA/OS5/APP10 and PLA/OS7/APP10 samples emitted only 40.2 and $36.0 \mathrm{MJ} \mathrm{m}^{-2}$, respectively. These samples, therefore, limited the total amount of fuel accessible for burning, which confirms the superior FR properties of these samples. The combination of OS and APP makes the samples more flame-resistant. The formation of intumescent char on matrix surface improves the thermal insulation between the flame and material's surface. This extinguishes the flame by preventing access to combustible gases and oxygen at the site of the fire [21]. 


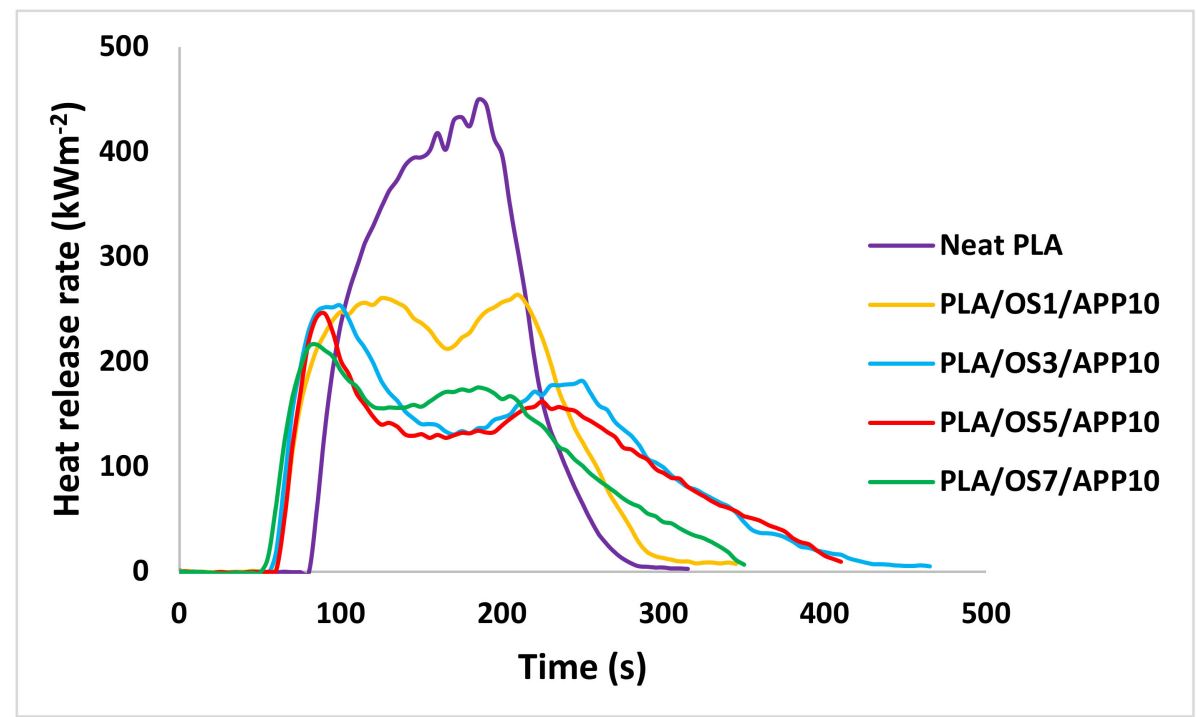

Figure 8. Heat release rate of samples (PLA = polylactic acid; OS = oxidized starch; $\mathrm{APP}=$ ammonium polyphosphate).

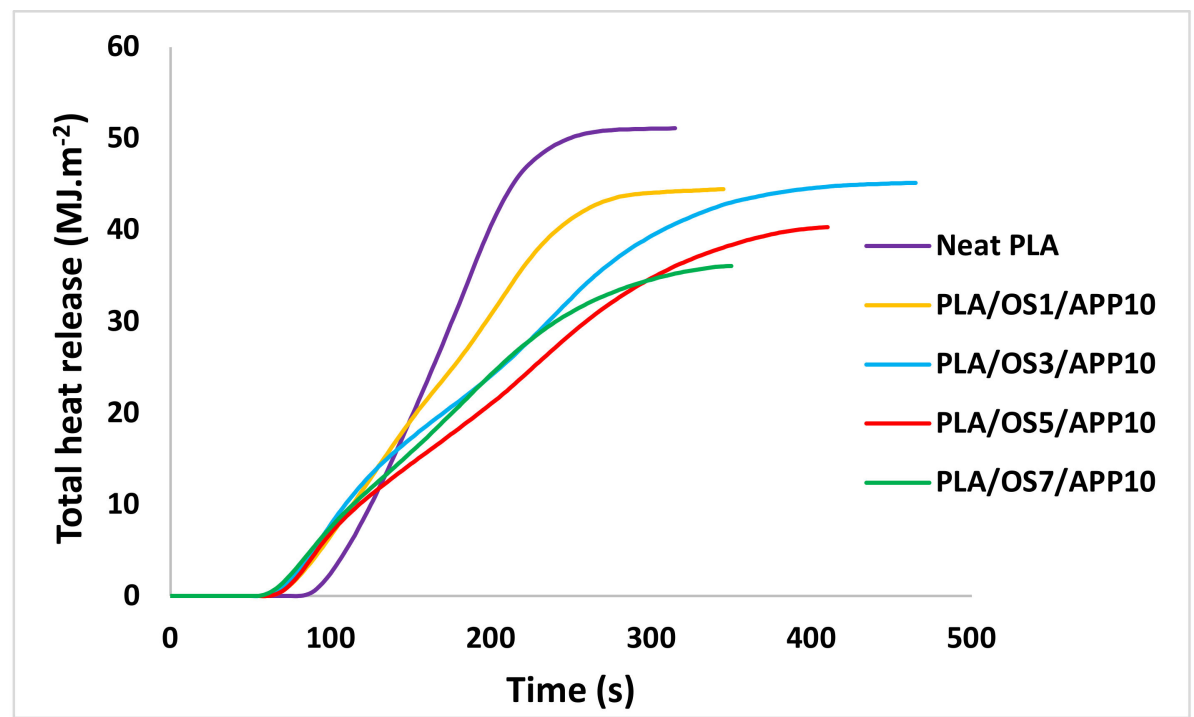

Figure 9. Total heat release of samples (PLA = polylactic acid; OS = oxidized starch; APP = ammonium polyphosphate).

Table 7 shows the residual mass\% after burning for pure PLA and PLA/OS/APP samples. No residual mass was left following the burning of pure PLA, but PLA/OS5/APP10 and PLA/OS7/APP10 left mass residues corresponding to $29.1 \%$ and $33.5 \%$ of the starting mass, respectively, as shown in Table 7. The relatively large proportion of residual mass (char residue) for PLA/OS7/APP10 probably reflects the development of char layer that hindered the passage of fuel and heat during combustion.

Compared to pure PLA sample, a significant decrease in effective heat of combustion (EHC) can be observed in the case of gas phase flame-retardant action (Table 7). EHC data of unfilled PLA and specimens containing OS/APP are presented in Table 7. The samples containing 1,3,5 and $7 \mathrm{wt} \%$ of OS showed lower EHC values compared to pure PLA because in the case of these samples, inhibition of flame occurred with partial combustion, therefore, lower mass loss of the samples was observed [35]. The combustion of a material not only gives information about the release of volatile compounds and smoke but also provides an indication about the burning mechanism [36]. For example, a higher smoke production is initiated, by an unfinished oxidation of gaseous products, that means a flame is inhibited 
by radical ensnaring reactions in the gaseous phase [37]. On the other hand, a reduction in the smoke discharge shows a well-ventilated burning process, in which flame inhibition is achieved by either the thermal barrier or dilution of the fuel [38]. For this reason, total smoke production were evaluated and the resultant values are reported in Table 7. It can be seen in Table 7 that samples containing 1 and $3 \mathrm{wt} \%$ of OS showed a comparatively higher total smoke production (TSP) than samples containing 5 and $7 \mathrm{wt} \%$ of OS. The release of higher TSP in case of samples containing 1 and $3 \mathrm{wt} \%$ of OS is mainly due to partial oxidation of the gaseous products. On the other hand, higher wt $\%$ of OS (5 and $7 \mathrm{wt} \%$ ) showed a significant reduction in TSP due to well ventilated combustion process by a complete oxidation of the developed gaseous products. Remarkably, the blends containing $7 \mathrm{wt} \%$ of OS showed the lowest TSP without conceding the other flame-retardant (FR) properties. This can be attributed to the reactions taken place between the APP and higher concentration of OS that enhanced the oxidation of the produced gaseous products and also by the formation of char layer in the condensed phase [39].

\subsubsection{Mechanism of Char Formation}

APP was used as flame retardant in PLA polymer. Upon decomposition of APP, phosphoric acid and ammonia was formed. Phosphoric acid acted as an acid catalyst in the dehydration process of hydroxyl groups in oxidized starch. Upon reaction of acid catalyst (phosphoric acid) with hydroxyl groups in oxidized starch, phosphate esters were formed that were decomposed and dehydration of oxidized starch took place. In the gas phase, the emission of carbon dioxide helped in dilution of the oxygen present in air together with the by-products that were ignited during decomposition of the materials, whereas the resultant char layer in the condensed phase protected the underlying polymeric material from further burning by restricting the free passage of radiant heat and oxygen.

\subsubsection{Analysis of Char Residues}

The images of the sample residues after the cone calorimetry test are shown in Figure 10. There was no residue left from the pure PLA sample as it was completely burnt. The residues of the sample containing $1 \mathrm{wt} \%$ of OS was relatively thin and virtually negligible, although this sample showed some charring characteristic. However, the sample with $3 \mathrm{wt} \%$ of OS slightly increased the char residues, even though the existence of open spaces in char residues (porous and loose surface) led to the development of a weak protective layer. Moreover, fabric samples with 5 and $7 \mathrm{wt} \%$ of OS displayed relatively higher char residues: in the PLA/OS7/APP10 sample in particular, a very compact and coherent char layer was formed that protected the sample from further burning and against external heat flux therefore, reduced the discharge of flammable gases from the sample [27]. Importantly, the blend of higher $w \mathrm{t} \%$ of OS with APP not only enhanced the char residues but also led to the development of established char layer having barrier properties against the discharge of flammable gases and external heat flux [40]. 

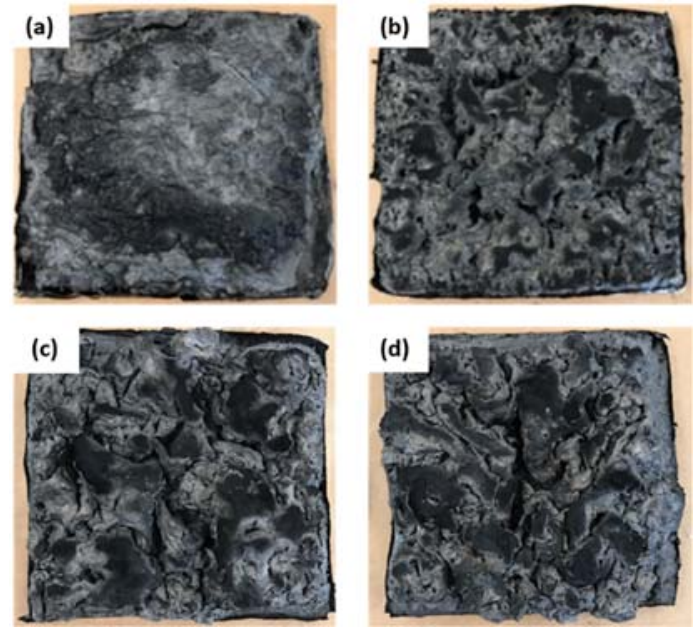

Figure 10. Char residues of (a) PLA/OS1/APP10, (b) PLA/OS3/APP10, (c) PLA/OS5/APP10 and (d) PLA/OS7/APP10 samples after cone calorimetry (PLA = polylactic acid; OS = oxidized starch; $\mathrm{APP}=$ ammonium polyphosphate)

The surface morphology of char residues was further investigated by SEM analysis to study the structure of the charred layer as shown in Figure 11. It was noticed that the surface morphology of charred layer produced by the PLA/OS7/APP10 fabric sample was more compact and denser due to enhanced char production by the interaction of OS and APP that resulted in a firm and steady protective char layer, which enhanced fire protection [41].
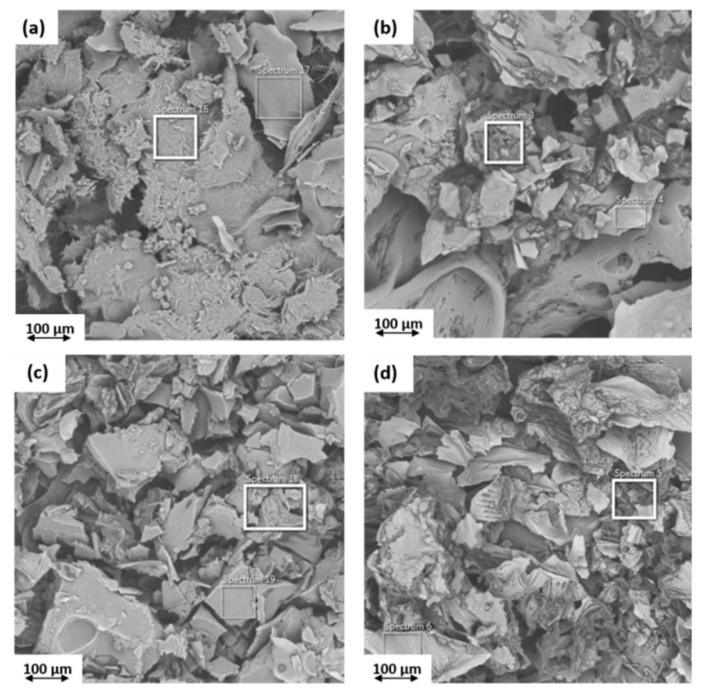

Figure 11. Surface morphology of char residues (a) PLA/OS1/APP10, (b) PLA/OS3/APP10, (c) PLA/OS5/APP10 and (d) PLA/OS7/APP10 (PLA = polylactic acid; OS = oxidized starch; $\mathrm{APP}=$ ammonium polyphosphate)

The char residues of fabric samples containing 1 and $3 \mathrm{wt} \%$ of OS were relatively less compact and dense as some holes on the surface can be seen in Figure 11, compared to samples containing 5 and $7 \mathrm{wt} \%$ of OS. Conversely, the samples containing $1 \mathrm{wt} \%$ of OS did not produce an intact charred layer after combustion due to which a porous and loose char structure was produced. Degradation of flame-retardant fabrics happens in different phases depending on fiber and flame-retardant type [42]. Therefore, the oxidizing agent (sodium perborate) used to develop oxidized starch in this study is biodegradable and, hence, will have potentially no environmental consequences. 


\subsubsection{FTIR Spectra of Non-Woven Fabric before and after Burning}

FTIR spectra of the non-woven fabric containing $7 \mathrm{wt} \%$ of OS (PLA/OS7/APP10) before and after burning are presented in Figure 12a,b respectively.

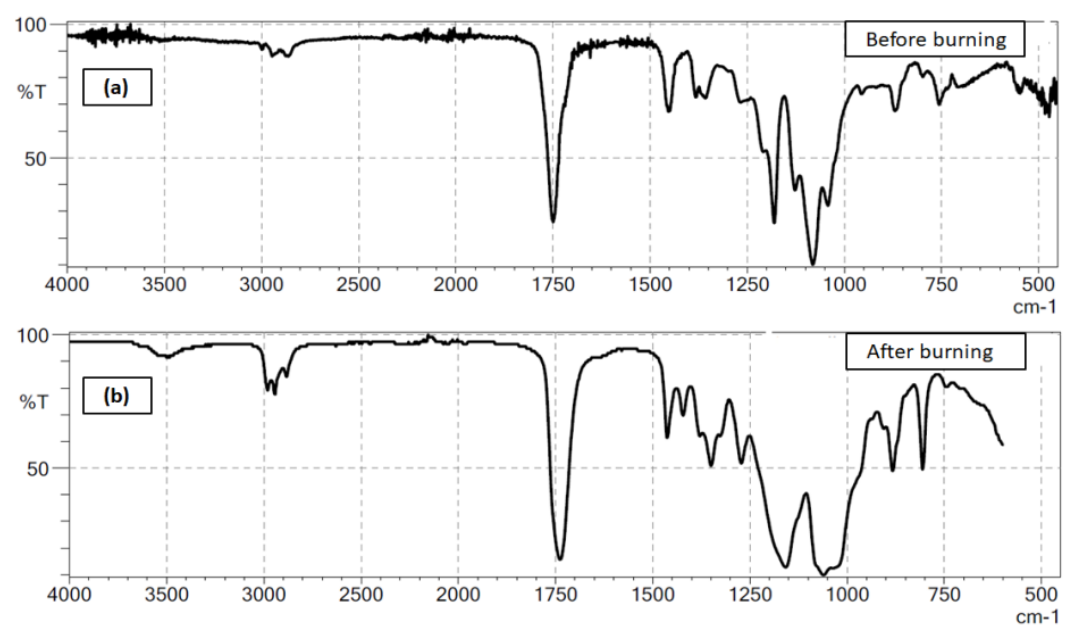

Figure 12. Fourier transform infrared (FTIR) spectra of PLA/OS7/APP10 non-woven fabric (a) before burning (b) after burning

The peak shown at $1190 \mathrm{~cm}^{-1}$ in Figure 12a is allocated to the C-O-C stretching vibrations. A broad and a sharp peak at $1745 \mathrm{~cm}^{-1}$ relates to the existence of carbonyl ester group which signifies the presence of OS on the backbone of PLA. The peaks presented at $1300-1450 \mathrm{~cm}^{-1}$ actually show the strongly attached water molecules in the starch. The peaks visualized in the regions of $2960-2790 \mathrm{~cm}^{-1}$ correspond to $\mathrm{C}-\mathrm{H}$ stretching vibrations. In Figure $12 \mathrm{~b}$ the existence of the absorption peak in the range of 1250-1100 is associated with the adsorption band of phosphoric acid which was formed by the decomposition of APP. In addition to that, the existence of a short peak at $2976 \mathrm{~cm}^{-1}$ is associated to the $\mathrm{OH}$ bending. It was observed that the existence of multiple absorption peaks of carbonyl groups between 1250 and $1500 \mathrm{~cm}^{-1}$ are associated with the development of carbonyl and carboxyl groups due to the oxidation of starch by the oxidizing agent.

\section{Conclusions}

In this study, modified starch oxidized by SPB was used as carbonization agent in intumescent flame-retardant blends. PLA/OS/APP blends containing different $w \mathrm{t} \%$ of OS were melt-blended using a twin screw extruder and then melt spun on a pilot-scale melt-spinning machine to develop flame-retardant multifilament fibers. The impact of oxidized starch together with ammonium polyphosphate was thoroughly investigated by optimizing melt-spinnability, mechanical and thermal behavior of PLA multifilament fibers. These multifilament fibers were cut into short fibers, carded to form fibrous web and later needle-punched together to form non-woven fabrics. The fire-related properties of these non-woven fabrics were tested by a cone calorimetry test. SEM analysis of multifilament fibers revealed reasonably uniform dispersion of the additives incorporated in the blends; however, some small agglomerates were also observed. The multifilament fibers containing $7 \mathrm{wt} \%$ of OS showed the highest thermal stability as confirmed by TG analysis alongside the residual mass $\%$ up to $14.1 \%$. Cone calorimetry revealed that the interaction between OS and APP stimulated a remarkable decrease in PHRR and THR of the non-woven fabric samples. For instance, the lowest PHRR $\left(216.1 \mathrm{~kW} \mathrm{~m}^{-2}\right.$ ) was observed in the case of a fabric sample containing $7 \mathrm{wt} \%$ of OS which, is $51.8 \%$ lower than the PHRR of the pure PLA sample. Similarly, THR of the same sample $(7 \mathrm{wt} \%$ OS) was $36.0 \mathrm{MJ} \mathrm{m}^{-2}$ which, is $29.5 \%$ lower than the THR of pure PLA sample. On the other hand, effective heat of combustion and total smoke production were significantly reduced in the case of samples containing higher $\mathrm{wt} \%$ of OS. The morphology of char leftovers confirmed that compact char 
structure is mainly responsible for enhanced flame-retardant properties of the samples. To conclude this concisely, oxidized starch (OS) not only improved the spinnability of PLA/OS/APP blends compared to native starch (NS) but also the flame-retardant properties of non-wovens were very promising for use in industrial applications.

Author Contributions: Conceptualization, M.M. and G.S.; methodology, M.M.; software, M.M.; validation, M.M.; formal analysis, M.M.; investigation, M.M.; resources, G.S.; data curation, M.M.; writing-original draft preparation, M.M.; writing—review and editing, G.S.; visualization, M.M.; supervision, G.S.; project administration, M.M.; funding acquisition, G.S. All authors have read and agreed to the published version of the manuscript.

Funding: This research was funded by [Operational Programme South Netherlands], grant number [35930032N] under the project BioTex Fieldlab and the APC was funded by the same funding agency.

Acknowledgments: The authors would like to acknowledge Chemelot Innovation and Learning Labs (Brightlands Chemelot Campus, Geleen), SABIC Innovative Plastics (Bergen op Zoom), and DSM Engineering Plastics (Geleen) for their technical support in fire testing. The authors would also like to acknowledge TWE Meulebeke BVBA (Belgium) for their technical support in producing non-wovens.

Conflicts of Interest: The authors declare no conflict of interest.

\section{References}

1. Murariu, M.; Dechief, A.; Ramy-ratiarison, R.; Paint, Y.; Raquez, J.; Dubois, P.; Murariu, M.; Dechief, A.; Ramy-ratiarison, R.; Paint, Y. Recent advances in production of poly(lactic acid) (PLA) nanocomposites: A versatile method to tune crystallization properties of PLA. Nanocomposites 2014, 1, 71-82. [CrossRef]

2. Rissanen, M.; Puolakka, A.; Hukka, T.; Ella, V.; Nousiainen, P.; Kellomaki, M. Effect of process parameters on properties of wet-spun poly (L,D-lactide) copolymer multifilament fibers. J. Appl. Polym. Sci. 2009, 113, 2683-2692. [CrossRef]

3. Yingfeng, Z.U.O.; Jiyou, G.; Jun, C.; Al, E. Effect of Starch/Polylactic Acid Ratio on the Interdependence of Two-Phase and the Properties of Composites. J. Appl. Polym. Sci. 2013, 30, 1108-1114. [CrossRef]

4. Mujica-Garcia, A.; Hooshmand, S.; Skrifvars, M.; Al, E. Poly(lactic acid) melt-spun fibers reinforced with functionalized cellulose nanocrystals. RSC Adv. 2016, 6, 9221-9231. [CrossRef]

5. Thakore, I.M.; Iyer, S.; Desai, A.; Lele, A.; Devi, S. Morphology, Thermomechanical Properties and Biodegradability of Low Density Polyethylene/Starch Blends. J. Appl. Polym. Sci. 1999, 74, 2791-2802. [CrossRef]

6. Kanerva, M.; Puolakka, A.; Takala, T.M.; Elert, A.M.; Mylläri, V.; Jönkkäri, I.; Sarlin, E.; Seitsonen, J.; Ruokolainen, J.; Saris, P.; et al. Antibacterial polymer fibres by rosin compounding and melt-spinning. Mater. Today Commun. 2019, 20, 100527. [CrossRef]

7. Rosa, D.; Lopes, D.; Calil, M. The influence of the structure of starch on the mechanical, morphological and thermal properties of poly (e-caprolactone ) in starch blends. J. Mater. Sci. 2007, 42, 2323-2328. [CrossRef]

8. Ramkumar, D.; Bhattacharya, M. Effect of crystallinity on the mechanical properties of starch/synthetic polymer blends. J. Mater. Sci. 1997, 32, 2565-2572. [CrossRef]

9. Liu, Y.; Mo, X.; Pang, J.; Yang, F. Effects of silica on the morphology, structure, and properties of thermoplastic cassava starch/poly(vinyl alcohol) blends. J. Appl. Polym. Sci. 2016, 133, 1-9. [CrossRef]

10. Jompang, L.; Thumsorn, S.; Wong, J.; Surin, P. Poly (lactic acid) and Poly (butylene succinate) Blend Fibers Prepared by Melt Spinning Technique. Energy Procedia 2013, 34, 493-499. [CrossRef]

11. Pivsa-Art, W.; Pivsa-Art, S.; Fujii, K.; Nomura, K.; Ishimoto, K.; Aso, Y.; Yamane, H.; Ohara, H. Compression molding and melt-spinning of the blends of poly (lactic acid) and poly (butylene succinate- co -adipate). J. Appl. Polym. Sci. 2015, 132, 1-9. [CrossRef]

12. Vignon, A.; Ayoub, A.; Massardier, V. The Effect of c -Irradiation and Reactive Extrusion on the Structure and Properties of Polycarbonate and Starch Blends: A Work Oriented to the Recycling of Thermoplastic Wastes. J. Appl. Polym. Sci. 2013, 127, 4169-4176. [CrossRef]

13. Dicastillo, C.; Rao, K.; Garrido, L.; Pereira, A.; Galotto, M. Novel Polyvinyl Alcohol/Starch Electrospun Fibers as a Strategy to Disperse Cellulose Nanocrystals into Poly (lactic acid). Polymers 2017, 9, 117. [CrossRef] [PubMed]

14. Hebeish, A.; Rabie, A.M.; El-naggar, M.E. Ultra-Microstructural Features of Perborate Oxidized Starch. J. Appl. Polym. Sci. 2014, 131, 40170-40179. [CrossRef] 
15. Albano, M.; Garrido, L.; Plucknett, K.; Genova, L. Influence of starch content and sintering temperature on the microstructure of porous yttria-stabilized zirconia tapes. J. Mater. Sci. 2009, 44, 2581-2589. [CrossRef]

16. Hamad, K.; Kaseem, M.; Ayyoob, M.; Joo, J.; Deri, F. Polylactic acid blends: The future of green, light and tough. Prog. Polym. Sci. 2018, 85, 83-127. [CrossRef]

17. Ayoub, A.; Rizvi, S.S.H. Properties of Supercritical Fluid Extrusion-Based Crosslinked Starch Extrudates. J. Appl. Polym. Sci. 2008, 107, 3663-3671. [CrossRef]

18. Park, H.; Lee, W.; Park, C. Environmentally friendly polymer hybrids. J. Mater. Sci. 2003, 38, 909-915. [CrossRef]

19. Chow, W.S.; Teoh, E.L. Flame retarded poly (lactic acid): A review. Express Polym. Lett. 2018, 12, $396-417$. [CrossRef]

20. Mostafa, K.; El-Sanabary, A. Graft Polymerization of Different Monomers onto Carbamated Starches Derived from Native and Hydrolyzed Starches. J. Appl. Polym. Sci. 2003, 88, 959-965. [CrossRef]

21. Maqsood, M.; Seide, G. Investigation of the Flammability and Thermal Stability of Halogen-Free Intumescent System in Biopolymer Composites Containing Biobased Carbonization Agent and Mechanism of Their Char Formation. Polymers 2018, 11, 48. [CrossRef] [PubMed]

22. Maqsood, M.; Langensiepen, F.; Seide, G. The Efficiency of Biobased Carbonization Agent and Intumescent Flame Retardant on Flame Retardancy of Biopolymer Composites and Investigation of their melt spinnability. Molecules 2019, 24, 1513. [CrossRef] [PubMed]

23. Wang, J.; Ren, Q.; Zheng, W.; Zhai, W. Improved flame-retardant properties of poly(lactic acid) foams using starch as a natural charring agent. Ind. Eng. Chem. Res. 2014, 53, 1422-1430. [CrossRef]

24. Salimi, K.; Topuzogullari, M.; Dincer, S.; Aydin, H.M. Microwave-assisted green approach for graft copolymerization of L -lactic acid onto starch. J. Appl. Polym. Sci. 2016, 133, 42937-42944. [CrossRef]

25. Zhiqiang, L.; Yi, F.; Su, Y. Thermoplastic Starch/PVAl Compounds: Preparation, Processing and Properties. J. Appl. Polym. Sci. 1999, 74, 2667-2673.

26. Mittal, V.; Akhtar, T.; Luckachan, G. PLA, TPS and PCL binary and ternary blends: Structural characterization and time-dependent morphological changes. Colloid Polym. Sci. 2015, 293, 573-585. [CrossRef]

27. Chapple, S.; Anandjiwala, R.; Ray, S. Mechanical, thermal, and fire properties of polylactide/starch blend/clay composites. J. Therm. Anal. Calorim. 2013, 113, 703-712. [CrossRef]

28. Solarski, S.; Mahjoubi, F.; Ferreira, M.; Devaux, E.; Bachelet, P.; Bourbigot, S.; Delobel, R.; Coszach, P.; Murariu, M.; Da Silva Ferreira, A.; et al. (Plasticized) Polylactide/clay nanocomposite textile: Thermal, mechanical, shrinkage and fire properties. J. Mater. Sci. 2007, 42, 5105-5117. [CrossRef]

29. Mngomezulu, M.E.; Luyt, A.S.; John, M.J. Morphology, thermal and dynamic mechanical properties of poly(lactic acid)/expandable graphite (PLA/EG) flame retardant composites. J. Thermoplast. Compos. Mater. 2017, 32, 89-107. [CrossRef]

30. Depeng, L.; Chixiang, L.; Xiulei, J.; Tao, L.; Ling, Z. Synergistic effects of intumescent flame retardant and nano-CaCO 3 on foamability and flame-retardant property of polypropylene composites foams. J. Cell. Plast. 2017, 54, 615-631. [CrossRef]

31. Fukushima, K.; Murariu, M.; Camino, G.; Dubois, P. Effect of expanded graphite/layered-silicate clay on thermal, mechanical and fire retardant properties of poly(lactic acid). Polym. Degrad. Stab. 2010, 95, 1063-1076. [CrossRef]

32. Lin, H.J.; Liu, S.R.; Han, L.J.; Wang, X.M.; Bian, Y.J.; Dong, L.S. Effect of a phosphorus-containing oligomer on flame-retardant, rheological and mechanical properties of poly (lactic acid). Polym. Degrad. Stab. 2013, 98, 1389-1396. [CrossRef]

33. Maqsood, M.; Langensiepen, F.; Seide, G. Investigation of melt spinnability of plasticized polylactic acid biocomposites-containing intumescent flame retardant. J. Therm. Anal. Calorim. 2019, 139, 305-318. [CrossRef]

34. Katsoulis, C.; Kandare, E.; Kandola, B.K. The combined effect of epoxy nanocomposites and phosphorus flame retardant additives on thermal and fire reaction properties of fiber-reinforced composites. J. Fire Sci. 2011, 29, 361-383. [CrossRef]

35. Wang, K.; Wang, J.; Zhao, D.; Zhai, W. Preparation of microcellular poly(lactic acid) composites foams with improved flame retardancy. J. Cell. Plast. 2017, 53, 45-63. [CrossRef]

36. Teoh, E.L.; Mariatti, M.; Chow, W.S. Thermal and Flame Resistant Properties of Poly (Lactic Acid)/Poly (Methyl Methacrylate) Blends Containing Halogen-free Flame Retardant. Procedia Chem. 2016, 19, 795-802. [CrossRef] 
37. Uddin, F. Flame-retardant fibrous materials in an aircraft. J. Ind. Text. 2016, 45, 1128-1169. [CrossRef]

38. Zhan, J.; Song, L.; Nie, S.; Hu, Y. Combustion properties and thermal degradation behavior of polylactide with an effective intumescent flame retardant. Polym. Degrad. Stab. 2009, 94, 291-296. [CrossRef]

39. Atabek Savas, L.; Mutlu, A.; Dike, A.S.; Tayfun, U.; Dogan, M. Effect of carbon fiber amount and length on flame retardant and mechanical properties of intumescent polypropylene composites. J. Compos. Mater. 2017, 52, 519-530. [CrossRef]

40. Bourbigot, S.; Duquesne, S.; Fontaine, G.; Bellayer, S.; Turf, T.; Samyn, F. Characterization and Reaction to Fire of Polymer Nanocomposites with and without Conventional Flame Retardants. Mol. Cryst. Liq. Cryst. 2008, 486, 37-41. [CrossRef]

41. Cheng, X.-W.; Guan, J.-P.; Tang, R.-C.; Liu, K.-Q. Improvement of flame retardancy of poly(lactic acid) nonwoven fabric with a phosphorus- containing flame retardant. J. Ind. Text. 2016, 46, 914-928. [CrossRef]

42. Yasin, S.; Behary, N.; Giraud, S.; Perwuelz, A. In situ degradation of organophosphorus fl ame retardant on cellulosic fabric using advanced oxidation process: A study on degradation and characterization. Polym. Degrad. Stab. 2016, 126,1-8. [CrossRef]

(C) 2020 by the authors. Licensee MDPI, Basel, Switzerland. This article is an open access article distributed under the terms and conditions of the Creative Commons Attribution (CC BY) license (http://creativecommons.org/licenses/by/4.0/). 